\title{
The Dynamics and Stochastics of Currency Betas Based on the Unbiasedness Hypothesis in Foreign Exchange Markets
}

\author{
Winston T. Lin \\ State University of New York at Buffalo, U.S.A. \\ Hong-Jen Lin \\ State University of New York at Buffalo, U.S.A. \\ Yueh H. Chen \\ National Sun Yat-sen University, Taiwan
}

\begin{abstract}
This article examines the dynamic and stochastic behavior of the beta coefficient (to be referred to as the currency beta) of the unbiasedness hypothesis (UH) in foreign exchange markets. We argue that the dynamics and stochastics of currency betas can be attributed to the dynamic behavior of various macroeconomic variables from different sectors of an economy, in addition to the trend variable considered in previous research. Incorporating four macroeconomic variables from the financial, real, and external sectors into the currency betas of eight currencies (developed and emerging) under a logarithmic change specification used to test the UH, we attempt to simultaneously test the behavior of currency betas in terms of nonstationarity, shifts in the mean and variance, and randomness. The vast quantity of empirical tests and results strongly suggests that the changing characteristics of currency betas are readily apparent and have important implications for the reconciliation of the controversies surrounding the legitimacy of the $\mathrm{UH}$, for government exchange rate policies, and for the forecasting of future spot rates, across the developed and emerging economies under study. We also find different tales from developed and developing countries (JEL F31, F37, F47, G15).
\end{abstract}

Keywords:four-step generalized, logarithmic change specification, macroeconomic variables, unbiasedness hypothesis, variable mean response

\footnotetext{
*The authors are very grateful to two anonymous referees of this journal for their insightful and constructive comments.
}

(Multinational Finance Journal, 2002, vol. 6, no. 3\&4, pp. 167-195)

(C) Multinational Finance Society, a nonprofit corporation. All rights reserved.

DOI: $10.17578 / 6-3 / 4-2$ 


\section{Introduction}

The unbiasedness hypothesis (UH), also known as the simple efficient market hypothesis, in the foreign exchange market, specifies that since the forward rate fully reflects available information concerning the investors $\varnothing$ expectations of the future spot rate, it is an unbiased predictor of the future spot rate (e.g., Levich [1979] and Lin [1999]). The question at issue is: Is the forward rate really an unbiased predictor of the future spot rate? Since the mid-1970, this question (hypothesis) has been intensively considered and tested with inconclusive and contradictory results.

Early studies either have confirmed (e.g., Cornell [1977]), rejected (e.g., Fama [1984]) the hypothesis, or have obtained mixed results (e.g., Domowitz and Hakkio [1985]). But much of the recent research has offered a negative answer to the question (e.g., Lin and Chen [1998], Barnhart et al. [1999], and Lin [1999]). A number of well-cited tests of unbiasedness suffer from specification error. For instance, with the exceptions of Gregory and McCurdy (1984), Chiang (1988), and Lin (1999), most studies devoted to testing the UH have suffered from structural homogeneity bias by assuming that the beta coefficient of the $\mathrm{UH}$ is invariant over time, due mainly to the limits of econometric methodologies. While specification error renders a test of unbiasedness invalid, the differences in the sample periods, time horizons (mostly one month), and currencies may lead to conflicting results. Nevertheless, there are two types of parameter variation, namely, dynamic (systematic) and stochastic (Rosenberg [1973]) and both types must be considered simultaneously and jointly (Belsley and Kuh [1973]).

Gregory and McCurdy (1984) have provided evidence rejecting a homogeneous structure for testing the UH and Chiang (1988) has tested the UH using a stochastic coefficient model. Barnhart and Szakmary (1991) have argued that the contradictory results found in the literature of tests of the UH depend upon the econometric specification used for testing the UH and differences in the sample period used for estimation. Recently, Lin (1999), using a trend function, has demonstrated that econometric specification and methodology, time periods, time horizons, and the dynamic and stochastic instability of the beta coefficient are major sources of the conflicting conclusions.

Given that the work by Barnhart and Szakmary (1991), Choi et al. (1998), and Lin (1999) has concluded that the beta (slope) coefficients 
in regressions testing the $\mathrm{UH}$ are unstable and follow a persistent trend through time, using a trend variable only to describe the dynamic and/or stochastic patterns of the currency beta of the UH, as did in Lin (1999), is not sufficient. In particular, Lin (1999, p. 210) has argued, he dynamics and stochastics of currency betas could be attributed to the dynamic behavior of various macroeconomic factors from different sectors of an economy, in addition to the trend variable. This could be an interesting project on its own. For example, the unexpected shocks of foreign exchange and interest rates from the financial sector, country stock return index from the real sector, and the balance of trade from the external sector, are potential choices This research extends and supplements the work of Lin (1999) by focusing attention on the contribution of the macroeconomic variables to the dynamic and stochastic behavior of currency betas, especially in light of the results in Lin (1999).

The empirical evidence strongly suggests that the fluctuating characteristics of currency betas render the UH invalid through time and that though the trend variable remains to be a powerful factor, the shock (unexpected change) of the foreign exchange rate is also a powerful contributor of the fluctuation patterns of currency betas, followed by the country stock return and the ratio of total foreign reserves to imports. The corroborating evidence indicates that the currency betas of those countries with pegging exchange rate policies tend to swing up and down with a wide range from month to month and, in some periods, with spikes, i.e., the interventions or manipulations of the monetary authorities amplify the fluctuations of currency betas. Finally, the explicit consideration of the dynamics and randomness of currency betas substantially increases the accuracy of forecasting future spot rates. Thus, provided that the UH has been intensively studied and the test results are inconclusive and contradictory, the topic re-examining the dynamics and stochastics of currency betas jointly across different countries (developed and emerging) is of special interest and crucial importance.

The remainder of the paper is organized in three sections. Section II specifies the theoretical model used to test the UH. Section III analyzes and discusses the empirical results. Finally, section IV concludes the study with some remarks. 


\section{Model Specification}

\section{A. The Logarithmic Change Specification}

The first step of model specification is the specification of an appropriate model for testing the UH. It is known that the UH in the logarithmic form is represented by

$$
\ln S_{j, t+m}=a_{j, m}+b_{j, m} \ln F_{j, t, m}+e_{j, t+m}
$$

where $S_{j, t+m}$ is the random future spot rate for currency $j$ prevailing $m$ periods (months) in the future, $F_{j, t, m}$ is the forward exchange rate for currency $j$ in period $t$ for delivery in $m$ periods (months), and $e_{j, t+m}$ is the random error with zero mean and constant variance , $t=1, T$, and $m=$ $1,3,6,12$. Model 1 is known to be the evel specification.

Another form used by Barnhart and Szakmary (1991) and others to test the UH is called the ercent change specification in which the change in the spot rate is regressed on the forward premium. As indicated in Boothe and Longworth (1986), Barnhart and Szakmary (1991), Lin (1999), and others, conflicting and inconclusive results from different specifications have been obtained. Those who have used the level specification 1 have not rejected the $\mathrm{UH}$, while those who have used the percent change specification have rejected it. As shown by Lin (1999), however, the spot and forward rates in the level and percent change forms have unit-roots and are co-integrated; and co-integration precludes a regression in levels and in pure first differences (i.e., percent changes) because there is no long-run solution (Taylor [1995]). To overcome the co-integration problem and because of the Siegel (1972) paradox, the appropriate specification testing the $\mathrm{UH}$ is:

$$
\begin{gathered}
\ln S_{j, t+m}-\ln S_{j, t-1+m}=\beta_{0, j, m} \\
+\beta_{j, m}\left(\ln S_{j, t-1+m}-\ln F_{j, t-1+m, m}\right)+v_{j, t+m},
\end{gathered}
$$

in which the change in the logarithmic spot rate is regressed onto the logarithmic forward premium (or discount) and $v_{j, t+m}$ denotes the normally distributed random error with zero 'mean. This is a very basic practice in the literature of foreign exchanges; and it is a standard 
practice to take logarithms in this literature due to the Siegel paradox (Lin [1999]). Like Lin (1999), equation 2 is referred to as the ogarithmic change specification and the beta (slope) coefficient, $\beta_{j, m}$, of the forward premium as the urrency beta of currency $j$. The model transformation of the UH as specified by equation 2 was used in Boothe and Longworth (1986) and Lin (1999) and is used again in this research. If we succeed in capturing the dynamics and stochastics of the currency beta, then the constant UH assumption is a serious specification error, that is, both the evel and ercent change models are misspecified and may cause serious consequences in the pricing and forecasting of future spot rates (Ghysels [1998], Lin [1999], and Lin and Lin [2000]).

\section{B. The VMR Specification}

To allow for simultaneous tests of the dynamics and stochastics of currency betas, the next step of model specification is the transformation of the logarithmic change specification into a variable mean response (VMR) model of random coefficients. To do this, let $Y_{j, m}(t)=\ln S_{j, t+m}-$ $\ln S_{j, t-1+m}$ and $X_{j, m}(t-1)=\ln S_{j, t-1+m}-\ln S_{j, t-1+\mathrm{m}}$. Then, equation 2 is transformed into a VMR random coefficients model composed of two equations given by:

$$
Y_{j, m}(t)=\beta_{0, j, m}+\beta_{j, m}(t) X_{j, m}(t-1)+v_{j, m}(t)
$$

and

$$
\beta_{j, m}(t)=\beta_{j, m}+\alpha_{j, m} f_{j, m}\left(t, Z_{j, m}(t)\right)+u_{j, m}(t)
$$

where $\beta_{j, m}$ and $\alpha_{j, m}$ are unknown constant coefficients independent of the trend variable $t, f_{j, m}\left(t, \boldsymbol{Z}_{j, m}(t)\right)$ is a function of $t$ and $\boldsymbol{Z}_{j, m}(t)$ denoting a row vector of macroeconomic variables or country-specific attributes, and $v_{j, m}(t)$ and $u_{j, m}(t)$ are random errors with zero means and constant variances $\sigma_{v, j, m}^{2}$ and $\sigma_{u, j, m}^{2}$, respectively. Thus, a significant $\sigma_{u, j, m}^{2}$ indicates the stochastics of currency beta $j$ and a significant $\alpha_{j, m}$ suggests the dynamics of the currency beta at $m$.

The theory underlying the VMR stochastic currency beta specification is the VMR random coefficients theory proposed by Hildreth and Houck (1968) and Theil (1971), and extended by Singh et 
al. (1976). The VMR specification of equations 3 and 4 involves two essential sources of random variation: the random disturbance in equation, $v_{j, m}(t)$, and the random error in the beta coefficient, $u_{j, m}(t)$.

In its original form, the $Z(t)$ vector does not appear in the specification. In other words, the dynamic and stochastic behavior of currency betas, $\beta_{j, m}(t)$, is subject to two fundamental impacts that cause them to deviate from their mean values, $\beta_{j, m}$ : One is the impact of the random error in the stochastically time-varying currency beta, $u_{j, m}(t)$, which has certain probability-distributional properties; and the other source of impact is the dynamic function, $f_{j, m}(t)$, which may shift systematically with the trend variable $(t)$. The former is stochastic and the latter is deterministic (see Singh et al. [1976], Lin et al. [1992], and Lin [1999] for more detailed explanations of the theoretical VMR specification). Thus, the appearance of $\boldsymbol{Z}_{j, m}(t)$ in the dynamic function represents a significant and important extension to the standard VMR specification.

The case in which $Z_{j, m}(t)$ is absent has been the subject of Lin (1999). Therefore, equation 4 in the presence of $\boldsymbol{Z}_{j, m}(t)$ represents an important and significant departure from Ballie and Bollerslev (1989), Barnhart and Szakmary (1991), Barnhart et al. (1999), Lin (1999), and others, suggesting that the dynamic and stochastic behavior of currency betas can be attributed to the dynamic behavior of various macroeconomic variables from different sectors of an economy, in addition to the trend variable considered in previous research (e.g., Lin [1999]).

For example, the unexpected shocks of foreign exchange rates (UF) and interest rates (UR) from the financial sector, the country stock return index (RCS) from the real sector, and the ratio of total foreign reserves to imports (TRIM) from the external sector are good candidates. These macroeconomic choices have been suggested at the very end of Lin (1999). Intuitively, the foreign exchange risk, reflected by the currency beta in equation 2 , could be influenced by the UF. The use of UR is justified by Blanchard (1981) and Chu and Tsaur (1987), which have elaborated the relationship among interest rate shocks, outputs, exchange rates and stock returns. The linkage between the RCS and currency markets is supported by Choi et al. (1998). The TRIM, measuring the comparative level of total foreign reserves, has been 
considered in Lin and Chen (1998). In addition, both the UR and UF have been used in Fisher and Tanner (1978), Zarnowitz (1985), Lin (1986, 1988), Lin and Chen (1998), and Lin and Lin (2000). Furthermore, a joint conditional $F$ test is shown in table 2 below to provide a justification from the statistical point of view.

An unexpected shock is treated as the discrepancy between the actual and the expected value, and the expected value is assumed to follow a third-order autoregressive (AR) process. For example, $U F_{j, t}=$ $S_{j, t}-S_{j, t}^{*}$ where $S_{j, t}^{*}$, the expected spot rate for currency $j$, is set equal to $S_{j, t-1} / 2+S_{j, t-2} / 3+S_{j, t-3} / 6$, which is actually a weighted average of three past actual values with weights of $1 / 2,1 / 3$, and 1/6. Such an AR(3) process has been used in a number of studies such as Fisher and Tanner (1978), Zarnowitz (1985), Lin (1986, 1988), Lin and Chen (1998), and Lin and Lin (2000), and shown to have an empirical appeal (a robust empirical evidence).

Finally, assuming linearity and $f_{j, m}\left(t, Z_{j, m}(t)\right)=t+t^{2}+$ macroeconomic variables, then equation 4 can be written as:

$$
\beta_{j, m}(t)=\beta_{j, m}+\alpha_{j, m} t+\gamma_{j, m} t^{2}+\sum_{\lambda=1}^{\Lambda} \theta_{\lambda, j, m} Z_{\lambda, j, m}(t)+u_{j, m}(t),
$$

and, upon combining equation 3 with equation 5 , we have

$$
\begin{aligned}
& Y_{j, m}(t)=\beta_{0, j, m}+\beta_{j, m} X_{j, m}(t-1)+\alpha_{j, m} X_{j, m}^{*}(t-1) \\
& +\gamma_{j, m} X_{j, m}^{* *}(t-1)+\sum_{\lambda=1}^{\Lambda} \theta_{\lambda, j, m} X_{\lambda, j, m}(t-1)+w_{j, m}(t),
\end{aligned}
$$

where, $X_{j m}^{*}(t-1)=t X_{j, m}(t-1), X_{j m}^{* * *}(t-1)=t^{2} X_{j, m}(t-1)$ and $X_{j, j, m}(t-1)$ $=Z_{j, j, m}(t) X_{j, m}(t-1)$ are composite regressors; and the composite error, $w_{j, m}(t)=u_{j, m}(t) X_{j, m}(t-1)+v_{j, m}(t)$ is heteroscedastic with a zero conditional mean and a conditional time-varying variance equal to $X_{j m}^{2}(t$ $-1) \sigma_{u j, m}^{2}+\sigma_{v, j, m}^{2}$, and is also serially correlated if both $u_{j, m}(t)$ and $v_{j, m}(t)$ are serially correlated. Equation 6 is nonlinear in $\mathrm{t}, X_{j, m}(t-1)$, and $Z_{j, j, m}(t)$.

\section{Statistical Hypotheses}


Within the framework of equation 6 , several statistical hypotheses can be set up to test the impact of the forward premium upon the spot rate change, the dynamics and stochastics of the currency beta for a currency, and the influence of the macroeconomic factors on currency betas. We argue that the presence of $\boldsymbol{Z}_{j, m}(t)$ contributes and leads to the changing characteristics (fluctuating patterns) of currency betas. More specifically, based on equation 6 , six statistical hypotheses of particular interest, denoted by $H_{0}^{1}, H_{0}^{2}$, to $H_{0}^{6}$, can be tested. First, we determine the impact of the forward premium on the change in the spot rate (the dependent variable in equation 6) by testing:

$$
H_{0}^{1} \text { with }\left\{\begin{array}{c}
H_{0}: \beta_{j, m}=0 \\
\text { versus } \\
H_{1}: \alpha_{j, m} \neq 0
\end{array}\right.
$$

The second and third hypotheses are needed to test whether a parabolic trend variable is more influential than a linear trend variable:

$$
H_{0}^{2} \text { with }\left\{\begin{array}{c}
H_{0}: \gamma_{j, m}=0 \text { and } \alpha_{j, m} \neq 0 \\
\text { versus } \\
H_{1}: \gamma_{j, m} \neq 0 \text { and } \alpha_{j, m} \neq 0 \text { or } \gamma_{j, m} \neq 0 \text { and } \alpha_{j, m}=0
\end{array}\right.
$$

and

$$
H_{0}^{3} \text { with }\left\{\begin{aligned}
& H_{0}: \alpha_{j, m}=0 \text { and } \gamma_{j, m}=0 \text { versus } \\
& H_{1}: \alpha_{j, m} \neq 0 \text { and } \gamma_{j, m}=0
\end{aligned}\right.
$$

Hypotheses $H_{0}^{2}$ and $H_{0}^{3}$ are actually nested. If $H_{1}$ in $H_{0}^{3}$ is not rejected, then $H_{0}^{2}$ should not be tested and it implies that the trend variable is quadratic (parabolic). On the other hand, if $H_{1}$ in $H_{0}^{2}$ is rejected, then $H_{0}^{3}$ should be tested; thus, if $H_{1}$ in $H_{0}^{3}$ is not rejected, then it implies that the trend variable is linear.

The fourth hypothesis is established to test how the macroeconomic 
variables under consideration jointly influence the dynamic and stochastic behavior of currency betas, i.e., the mean shifts caused by the macroeconomic variables. Therefore, we would like to test

$$
H_{0}^{4} \text { with }\left\{\begin{array}{l}
H_{0}: \theta_{1, j, m}=\theta_{2, j, m}=\theta_{3, j, m}=\theta_{4, j, m}=0 \\
\text { versus } \\
H_{1}: H_{0} \text { is not true }
\end{array}\right.
$$

$H_{0}^{4}$ requires a joint test to be examined by a conditional $F$ test. That is, controlling the intercept and trend variables in equation 6 , it is entirely possible to observe whether or not the economic variables in $\boldsymbol{Z}_{j, m}(t)$ affect currency betas.

The dynamics of the currency beta may be characterized by the nonstationarity in terms of the shift or heterogeneity of the variance of the currency beta. Therefore, we would like to test

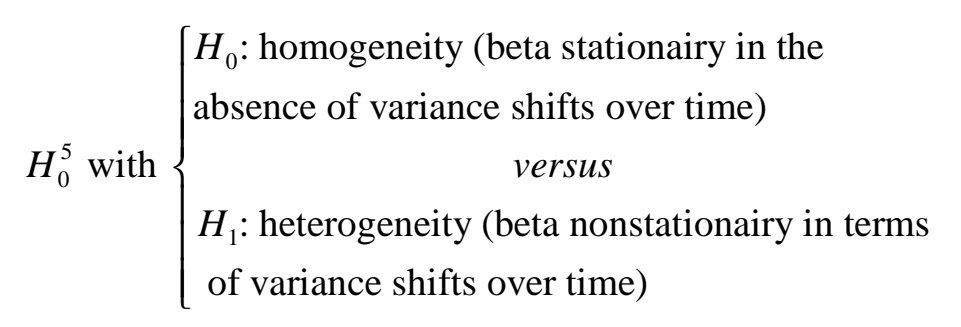

The test of Hypothesis $H_{0}^{5}$ is carried out by applying the five special tests $T^{*}, B, G, S^{\prime}$, and $W$ as nicely outlined in Lin (1999, Appendix II, pages 214-218, with the references of this five tests provided).

Finally, the randomness of the currency beta can be investigated by testing the following hypothesis:

$$
H_{0}^{4} \text { with }\left\{\begin{array}{l}
H_{0}: \sigma_{u, j, m}^{2}=0 \text { (the randomness hypothesis) } \\
\quad \text { versus } \\
H_{1}: \sigma_{u, j, m}^{2} \neq 0 \text { (the nonrandomness hypothesis) }
\end{array}\right.
$$


Hypothesis $H_{0}^{6}$ is tested by the traditional $t$-ratios from the four-step generalized least squares (FGLS) method.

\section{Empirical Analysis}

\section{A. Methods of Analysis}

The unit-root and co-integration tests of spot and forward rates are performed using the Dickey-Fuller (1979, 1981), Dickey-Pantula (1987), Phillips-Perron (Phillips and Perron [1988] and Perron [1988]) methods.

The violation of the normality of the random error is detected by conducting the Shapiro-Wilks (Shapiro and Wilk [1965]) $W$ test, the Mardia's Mardia (1980) skewness and kurtosis tests, and Henze and Zirkler's [Henze and Zirkler (1990)] $T$ test. The White's (1980) test is undertaken to detect the problem of heteroscedasticity.

More importantly, the four-step generalized least squares (FGLS) procedure, proposed by Hildreth and Houck (1968), Theil (1971), and Singh et al. (1976), and applied by Lin et al. (1992), Lin (1999) and Lin and Lin (2000), is programmed to estimate model (6). A brief description of the FGLS procedure can be found in Lin (1999, Appendix I, pages 210-214). For purposes of comparison, the OLS is also applied to estimate the "level" equation 1.

Note that, with monthly data used, and 3-, 6-, and 12- month forward contracts, there exists an overlapping data problem (Hansen and Hodrick [1980]) which causes the error terms in equation 6 to be autocorrelated (serially correlated). The problem of overlapping data or serial correlation cannot be simply assumed away and, as in Lin (1999), is solved by making use of the Newey-West (1987) adjustment to the variance-covariance matrices in the OLS and FGLS methods.

Moreover, to determine the validity of the VMR stochastic coefficients and to detect variance shifts (or heterogeneity), five special tests known as $T^{*}, B, G, S^{\prime}$, and $W$, as used in Lin et al. (1992) and Lin (1999), are undertaken. To test hypothesis $H_{0}^{4}$, a conditional $F$ test (section $\mathrm{F}$ below) is conducted. 


\section{B. Data and Data Sources}

The data used cover the time period from January 1985 to December 2000, yielding 192 monthly observations. The starting point is chosen because it is available to all the eight currencies under study. These currencies are the Canadian dollar (CN), French franc (FR), German Duetsche mark (GM), Japanese yen (JP), United Kingdom pound sterling (UK), Australian dollar (AU), new Taiwan dollar (TW), and Singapore dollar (SG). The first five constitute a group of currencies of developed countries and the other three form a group of currencies of emerging economies.

The spot and forward exchange rates for all countries were collected from the Datastream and The Wall Street Journal. The data are the rates reported at the end of each month.

The stock returns were collected from the Datastream, too. The London FTSE index for UK, Toronto TSE300 composite price index for $\mathrm{CN}$, Paris CAC40 industrial price index for FR, Frankfurt FAZ general

price index for GM, Tokyo NIKKEI 225 stock average price index for JP, Singapore Straits Times industrial price index for SG, Taiwan Stock Exchange weighted price index for TW, and Australian Stock Exchange all ordinary price index for AU, were used.

Domestic interest rates, consumer price indices, total foreign reserves, and total imports were collected from the International Financial Statistics (IFS). Here, the same consumer index is employed for the three different months in a quarter if monthly figures are not available. The real interest rate, defined as the ratio of the domestic interest rate to the consumer price index, was used.

\section{Unit-Roots, Normality and Heteroscedasticity Tests}

The results of the Dickey-Fuller (1979, 1981), Dickey-Pantula (1987), and Phillips-Perron (Phillips and Perron [1988] and Perron [1988]) tests have led to the conclusion that the spot and forward rates for all eight currencies under study are $I(1)$, consistent with many other studies such as Barnhart and Szakmary (1991), Bhawnani and Kadiyla (1997), Lin and Chen (1998), and Lin (1999). Thus, the logarithmic change specification (2) is an appropriate transformation of the UH (Taylor [1995] and Lin [1999]).

The statistical evidence has also suggested the violation of the 
normality assumption underlying the error terms. The rejection of normality of the error terms provides a good justification to use the FGLS to estimate the VMR random coefficients model. When the error terms are normally distributed, the FGLS estimator is asymptotically efficient. When the error terms are not normal, the FGLS tends to be more efficient. The White test for the heteroscedasticity of the composite error also supports the assumption of the FGLS method. Hence, both the normality and White tests justify the application of the FGLS approach.

\section{The OLS Estimates of Equation 1}

To demonstrate whether the standard (level) form of the UH is validated by the data, the OLS estimates of equation 1, the UH in its logarithmic form, were calculated. The $R^{2}$ 's decline as the time horizon lengthens in all currencies. Thus, under the normal circumstance, the shorter the horizon is, the more the indicative the standard UH model will be.

Statistically and empirically, the UH in its logarithmic form is not confirmed by the data for both the groups of developed and developing economies due to the fact that the intercepts differ statistically from zero and the slopes from one. The only exception is the $\mathrm{CN}$ case where the intercepts are insignificantly zero and the slopes are significantly close to one for all horizons. Therefore, it is concluded that the UH under the level specification is rejected overwhelmingly, though not totally, by the data. The conclusion is consistent comfortably with both Lin and Chen (1998) and Lin (1999).

\section{E. The FGLS Estimates of Equations 5 and 6}

As mentioned before, in the absence of macroeconomic variables, Lin (1999) has used three functional forms of $f(t)$, namely, the error-in-beta, the linearly dynamic trend, and the parabolically dynamic trend, to examine the relationship between the dynamic and stochastic instability of the currency beta and the UH, and found the existence of a persistent trend through time. The empirical finding lends a strong support to Barnhart and Szakmary (1991). In the present study, we also have considered these three functional forms in the absence of macroeconomic variables and reached the same conclusion for both the developed and emerging economies considered.

Here, we focus on the extension of these trend models by 
considering the trend variable jointly with some carefully selected macroeconomic variables from different sectors of an economy as suggested in Lin (1999). As indicated earlier, the macroeconomic variables chosen are UF and UR from the financial sector, RCS from the real sector, and TRIM from the external sector. The estimates of equations 5 and 6 obtained by the FGLS incorporating the Newey-West adjustment for the UK, JP, TW, and AU are reported in table 1.

Generally speaking, the $R^{2}$ 's and $t$-values decrease as the time horizon increases. The $R^{2}$ 's are higher when $m=1$ than when $m=3,6$, 12. The $\mathrm{CN}$ from the group of developed countries and the SG in the group of emerging economies are two exceptions (with relatively low coefficients of determination). Because of the close relation between Canada and the U.S., the variations of the exchange rates of the $\mathrm{CN}$ (expressed in terms of U.S. dollars) are comparatively small. Consequently, in the case of $\mathrm{CN}$, the difference between the logarithms of the spot and the forward rate (the independent variable) may not well explain the change in the logarithms of the future spot rates (the dependent variable). The monetary authority of the SG pegs its exchange rates in terms of U.S. dollars tightly. Nevertheless, a careful review of table 1 suggests some points of particular interest:

First of all, the estimates $\left(\hat{\beta}_{0}\right)$ of the constant term $\left(\beta_{0}\right)$ are significant at the $5 \%$ level at all time horizons in the cases of the UK, GM, and JP from the group of developed countries and in the case of the AU from the group of emerging economies. Consequently, these cases obviously do not comply with the requirement that the intercept of the UH differ insignificantly from zero.

In the second place, the null hypothesis of $H_{0}^{1}$ concerning the effect of the forward premium on the spot rate change is rejected for the UK and JP when $m=1,3,6,12$, for the CN when $m=1$, and for the FR and GM when $m=1,3,6$; but it is not rejected for the FR and GM when $m$ $=12$ and for the $\mathrm{CN}$ when $m=3,6,12$. As far as the developing economies are concerned, the null hypothesis of $\mathrm{H} 1$ is rejected for the SG when $m=1$, for the TW at $m=1,3,6$, and for the AU at $m=1,3$, 6,12 . Like the CN, it is not rejected for the $S G$ at $m=3,6,12$. Rejection of the null hypothesis implies a significant positive impact of the forward premium on the change in the spot rate if $\hat{\beta}>0$ such as the cases of the $\mathrm{UK}$ and $\mathrm{AU}$ at all horizons, but implies the significance of the forward discount if $\hat{\beta}<0$ such as the case of the GM at $m=1,3$. The 


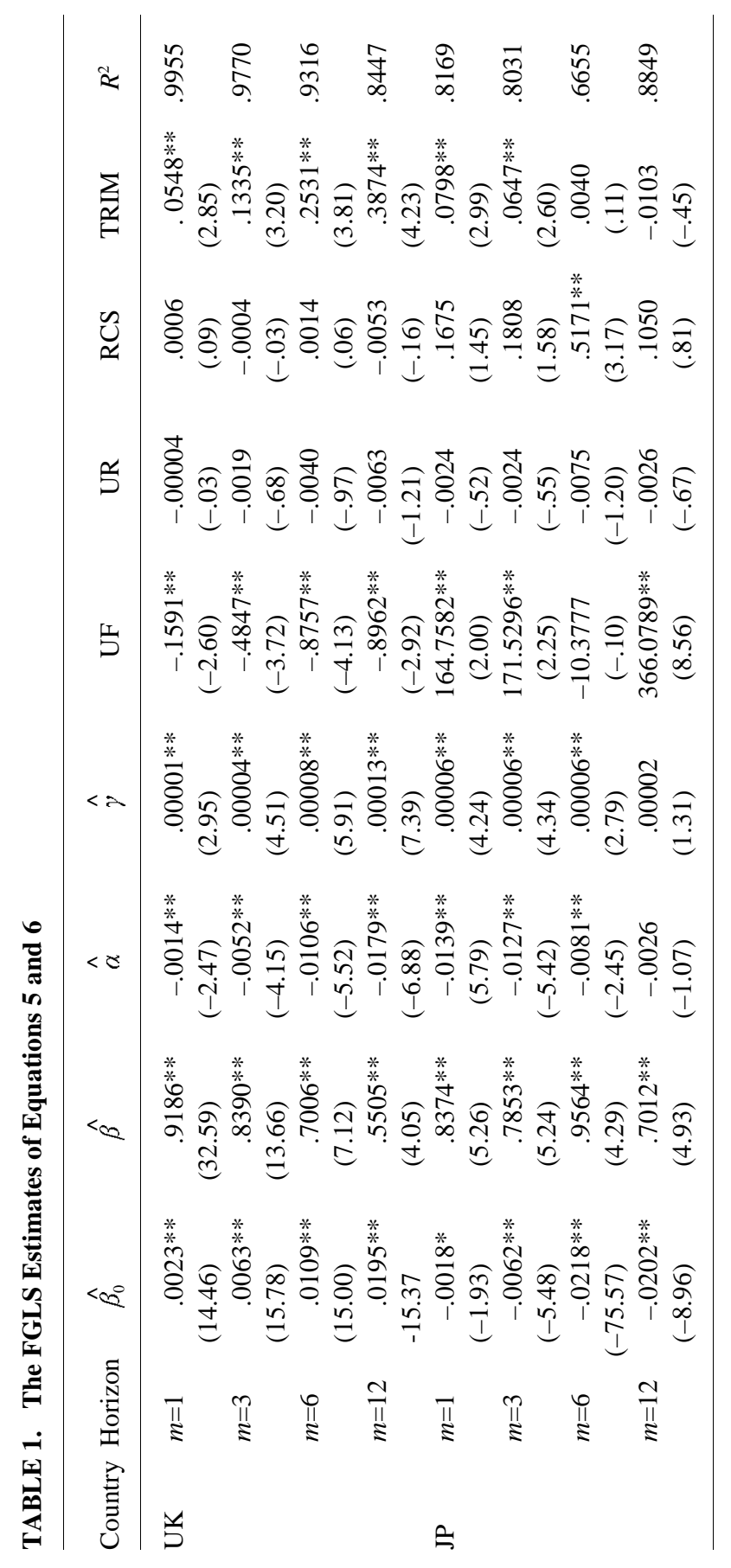




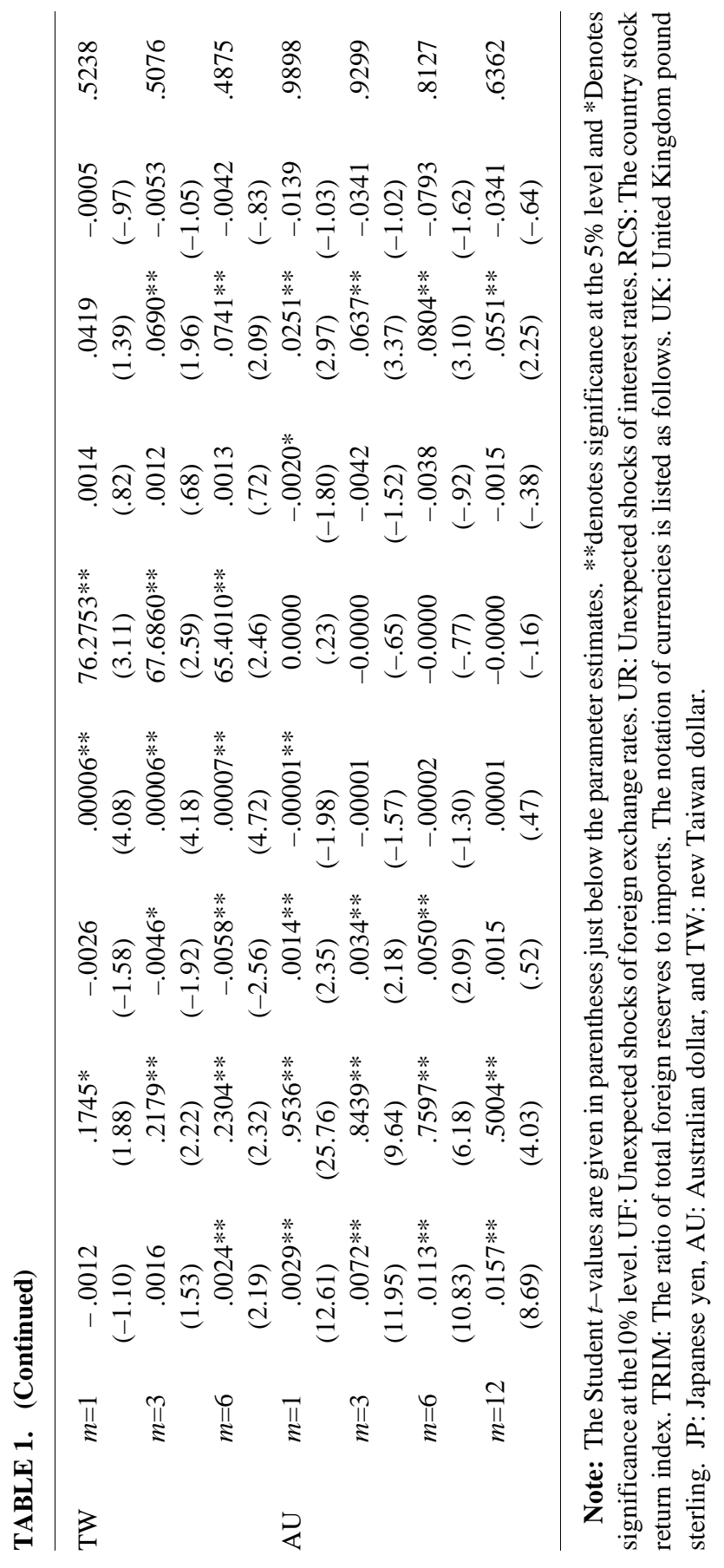


estimates of $\beta$ are positive in a great number of cases and are negative in just two cases as mentioned above (i.e., the GM at $m=1,3$ ).

In the third place, we also can observe from table 1 that in the group of developed countries, the alternative hypothesis $\left(H_{1}\right)$ in $H_{0}^{2}$ is not rejected, i.e., the parabolic trend factor is significant at all time horizons in the cases of the CN and UK; at $m=1,3,6$ in the case of the FR; at $m=1,3,12$ in the case of the GM; and at $m=1,3,6$ in the case of the JP. The situation in the group of emerging economies seems to be more complicated. The null hypothesis $\left(H_{0}\right)$ in $H_{0}^{3}$ is not rejected, i.e., both the parabolic and linear trends are not significant at all time horizons for the SG. The alternative hypothesis in $H_{0}^{2}$ is not rejected, i.e., the quadratic trend prevails at $m=1,3,6$ for the TW; and at $m=1$ for the AU. $H_{1}$ in $H_{0}^{3}$ is not rejected, that is, the trend variable appears to be linear in the case of the GM at $m=6$; and in the case of the AU at $m=3,6$. The test results lead us to conclude that there are only $3(9.7 \%)$ significant cases out of the 31 estimates $(\hat{\alpha})$ of the linear trend factor, coupled with insignificant estimates $(\hat{\gamma})$ of the parabolic trend variable. In other words, there are only 3 cases in which $H_{1}$ in $H_{0}^{3}$ is not rejected, suggesting that the trend factor is linear. In contrast, there are 23 (74.2\%) cases of the 31 estimates in which $H_{1}$ of $H_{0}^{2}$ is not rejected, implying that the trend variable is parabolic. This empirical evidence clearly implies that the quadratic trend variable is overwhelmingly more influential than the linear trend variable, and this is true for both the groups of currencies considered. Furthermore, comparing the two groups of countries, we find that the parabolic trend variable is more important for the developed countries than for the emerging economies. Note that Lin and Lin (2000) have observed that the country beta of Singapore follows a parabolic trend pattern; in contrast, in this research, we find that the currency beta of the SG does not exhibit any trend pattern at all.

In the last place, it is found that the impacts of the macroeconomic variables on the behavior of currency betas vary from a currency to another currency and from a time horizon to another time horizon, and also differ between the developed and emerging economies. For example, the impact of the UF variable on currency betas and on the changes in spot rates is significant at $5 \%$ level for the UK and GM at all time horizons; for the CN at $m=1,6,12$; for the JP at $m=1,3,12$; and 
for the SG and TW at $m=1,3,6$. But it is insignificant for the FR and AU cases. The directions of the impact caused by the UF variable are mixed: the influence is firmly negative for the UK and SG and is decisively positive for the JP and TW.

Based on the results, it appears that the UR variable is not an important factor to describe the behavior of currency betas and exchange rate changes. In contrast, the RCS variable is more important for the emerging economies than for the developed countries. The RCS variable is significant for the TW and GM at $m=3,6$; for the AU and $\mathrm{CN}$ at all time horizons; and for the JP at $m=6$. It is not significant at all time horizons for the UK, FR, and SG. In other words, the currency betas and the shifts in spot rates of the emerging economies (excluding the SG) seem to be more closely related to the movements of their stock markets than the developed countries (excluding the UK and FR). Finally, the TRIM variable exerts a positive impact on the currency betas and on the changes in spot rates in the cases of the UK and $\mathrm{CN}$ at all time horizons, in the case of the GM when $m=1,3,6$, in the case of the JP when $m=1,3$, and in the case of the AU when $m=3,12$; and no significantly negative effect is observed.

In sum, the impacts of macroeconomic variables upon the dynamics and stochastics of currency betas and upon the changes in foreign exchange rates are a complex matter. Not surprisingly, because the attributes (UF, UR, RCS, and TRIM) considered are country-specific, they exert impacts (in sign and in magnitude) on the foreign exchange markets of individual countries differently instead of uniformly. The discrepancies in the impacts of the macroeconomic variables from different sectors, also observed by, e.g., Burstein (1999) and Blanchard (1981), may possibly be partially explained by the long memory of the foreign exchange, stock, and money markets (Lo and MacKinlay [1999]). More importantly, we find different tales across developed and emerging economies which support the forward premium puzzle observed by Bansal and Dahlquist (2000). The ranking of the importance is $\mathrm{UF} \succ \mathrm{TRIM} \succ \mathrm{RCS} \succ \mathrm{UR}$ for the group of developed countries in comparison with the ranking of $\mathrm{UF} \succ \mathrm{RCS} \succ \mathrm{UR} \succ \mathrm{TRIM}$ for the group of developing economies. Among the four macroeconomic country-specific attributes, the UF stands out as the most influential attribute for both groups. But, according to the empirical results, the trend factor (especially the parabolic trend) remains as a powerful factor as the UF variable. 


\section{F. A Joint F Test for $\mathrm{H}_{0}^{4}$}

The above discussion of what the macroeconomic variables have contributed to the behavior of currency betas was done by treating these variables individually. A joint test is needed to determine the appropriateness of the four macroeconomic variables as a select group used to measure their collective contribution to the behavior of the currency beta of a country. In essence, a joint conditional $F$ test is required for testing hypothesis $H_{0}^{4}$. Given that the FGLS estimators in

equation 6 are known as $\hat{\beta}_{0}, \hat{\beta}, \hat{\alpha}$, and $\hat{\gamma}$, then using equation 6 the conditional dependent variable can be defined as:

$$
\begin{gathered}
Q_{j, m}(t)=Y_{j, m}(t)-\hat{\beta}_{0, j, m}-\hat{\beta}_{j, m} X_{j, m}(t-1) \\
-\hat{\alpha}_{j, m} X_{j, m}^{*}(t-1)-\hat{\gamma}_{j, m} X_{j, m}^{* *}(t-1) .
\end{gathered}
$$

Then, we regress $Q_{j, m}(t)$ on $X_{j, j, m}(t-1), \lambda=1,2,3,4$, that is, the following regression relationship denoted by equation 7 is estimated by the FGLS method:

$$
Q_{j, m}(t)=\delta_{j, m}+\sum_{\lambda=1}^{\Lambda} \theta_{\lambda, j, m} X_{\lambda, j, m}(t-1)+w_{j, m}(t)
$$

Accordingly, the $F$-ratios needed to test hypothesis $H_{0}^{4}$ can be calculated.

Table 2 demonstrates the outcome of $F$ tests where twenty-five $(81 \%)$ out of thirty-one cases are significant different from zero. In other words, the macroeconomic variables chosen play an inevitable role in explaining the dynamic and stochastic behavior of the currency betas for a majority of countries at time horizons under study.

\section{G. The Fluctuating Patterns of Currency Betas}

The currency beta function 5 is important for determining the validity of the UH. If the UH is valid, the beta value computed based on function 5 must be exactly equal to or at least close to one over time. The 


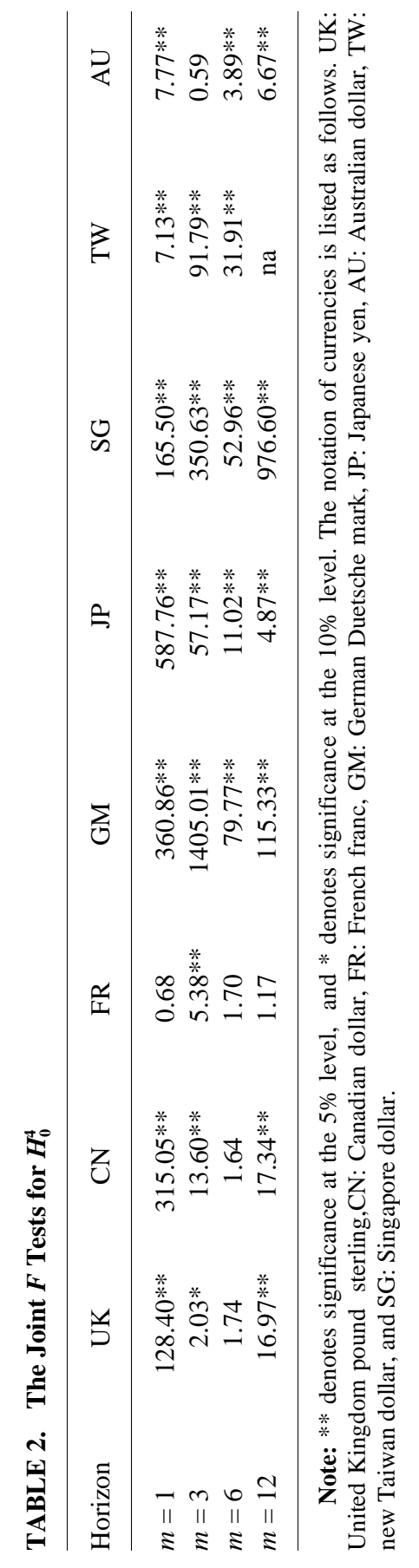




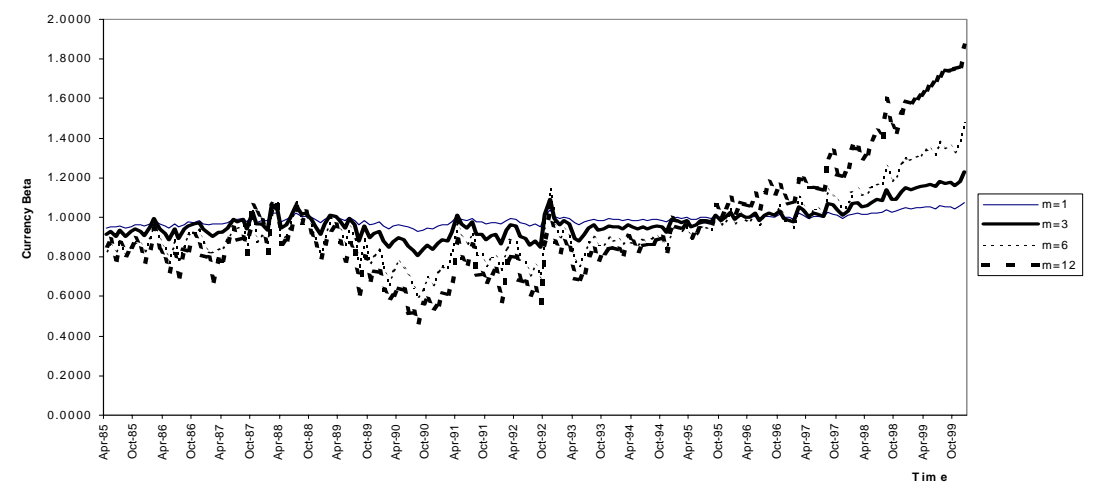

FIGURE 1.-The Pattern of the Currency Beta of UK.

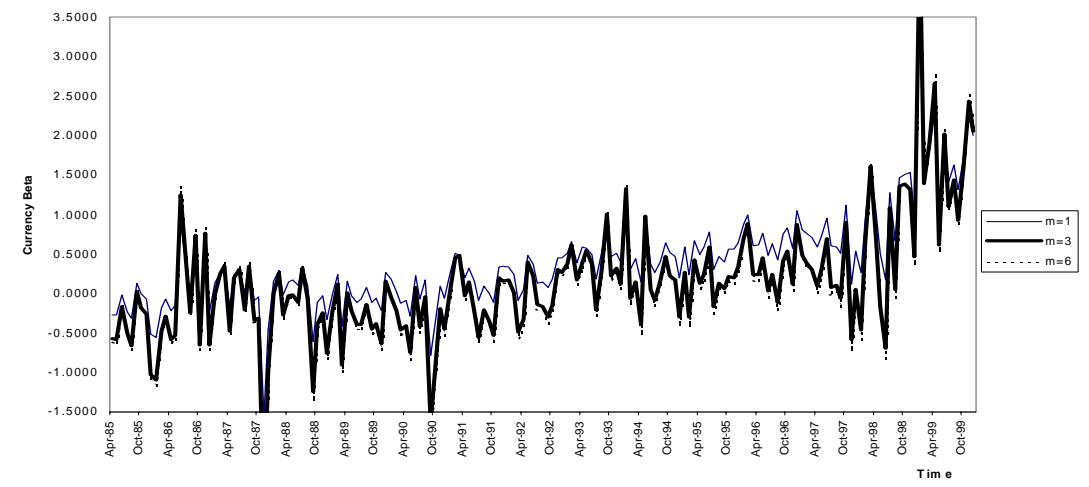

FIGURE 2.- The Pattern of the Currency Beta of the New Taiwan Dollar.

observed function 5 is plotted for UK and TW, as shown by figures 1-2 (figures for other countries considered are available upon request). In all cases, the currency beta of a country fluctuates over time and is highly sensitive to the turbulence caused by special events. For instance, the well-known global phenomenon of the stock crash taking place in October 1987 has caused the spikes of the currency betas of the countries, developed (e.g., the FR at $m=12$ and the GM and JP at $m=$ 6) and emerging (e.g., the SG at $m=3,12$, and TW and AU at all time 
horizons) under consideration. Another example is the Asian financial crisis starting with June 1997 which has led to the subsequent turmoil of the currency betas of the JP at $m=6$ and all the developing economies (e.g., the SG, TW, and AU at all time horizons) studied.

The currency betas of the developed countries and the emerging economies fluctuate in relatively large ranges, though the amplitudes of fluctuations may differ at different horizons. The figures of the changing characteristics of currency betas over time also clearly show that the decision of the monetary authority to pin its exchange rate down to the value of the U.S. dollar leads to the stability of the foreign exchange rate, but causes the fluctuation of the currency beta. In other words, the stabilization policy of the foreign exchange rate may not really stabilize the economy due to the large swings of currency betas. This is an important policy implication.

The fluctuating characteristics of currency betas strongly suggest that currency betas are time-varying through time and that the UH is firmly rejected, indicating that the forward rate is not an unbiased predictor of the future spot rate.

\section{H. Nonstationarity and Heterogeneity: Hypothesis $H_{0}^{5}$}

The five tests called $T^{*}, B, S, G$, and $W$ (refer to Appendix II in Lin, 1999 for details) have been performed to detect the possibility of nonstationarity in terms of the shift or heterogeneity of the variance of the currency beta under the logarithmic change specification testing the UH.

We find that the null hypothesis in $H_{0}^{5}$, i.e., the absence of variance shifts (or homogeneity) in the currency beta, was rejected for a majority of cases. For example, the null hypothesis was unanimously rejected by all the five tests in the case of the UK when $m=3$ and in the case of the FR when $m=1$. Therefore, the conclusion of the five tests provides additional evidence suggesting that the currency beta shifts over time and, consequently, the forward rate is not an unbiased predictor of the future spot rate. 


\section{The Stochastics of Currency Betas: $H_{0}^{6}$}

The test results of hypotheses $H_{0}^{1}-H_{0}^{5}$ describe the nature of the dynamics of currency betas, whereas hypothesis $H_{0}^{6}$ is designed to show the stochastics of currency betas. The estimates of the variance $\left(\sigma_{u, j, m}^{2}\right)$ of the random error $\left(u_{j, m}\right)$ in equation 5 are presented in table

3. In table 3, there are 31 entries among which $22(71.0 \%)$ are significant at the 5\% level, implying that the null hypothesis of $H_{0}^{6}$ is rejected for approximately $71 \%$ of the estimates. Thus, the significant estimates of the variances of currency betas firmly imply the stochastics of currency betas.

\section{J. Assessment of Forecasting Ability}

The level change specification and the logarithmic change specification used to test the UH can be further put on trial by evaluating their forecasting ability. To do this, we have computed the values of two accuracy measurements, namely, the mean absolute percentage error (MAPE) and Theil's $U^{*}$. Table 4 presents the results based on equation 1 , the level change specification in its logarithmic form, and equation 6 , the VMR stochastic coefficients transformation of the logarithmic change specification.

The values of the accuracy measurements indicate remarkable improvements of equation 6 over equation 1 for all the countries (developed and developing) under study at all time horizons, ranging from as high as $99.77 \%$ measured by both MAPE and $U^{*}$ in the case of the AU at $m=1$ to $19.18 \%$ measured by MAPE in the case of the SG at $m=1$. The most significant one is associated with the AU where the percentage improvement is close to $100 \%$ gauged by both MAPE and $U^{*}$ at all four horizons. There are only three values indicating that the accuracy of forecasting worsens. These are seen in the case of the GM at $m=3$ and in the case of the SG at $m=1,3$, all measured by positive percentage changes of $U^{*}(48.79,70.99$, and 38.42, respectively). 


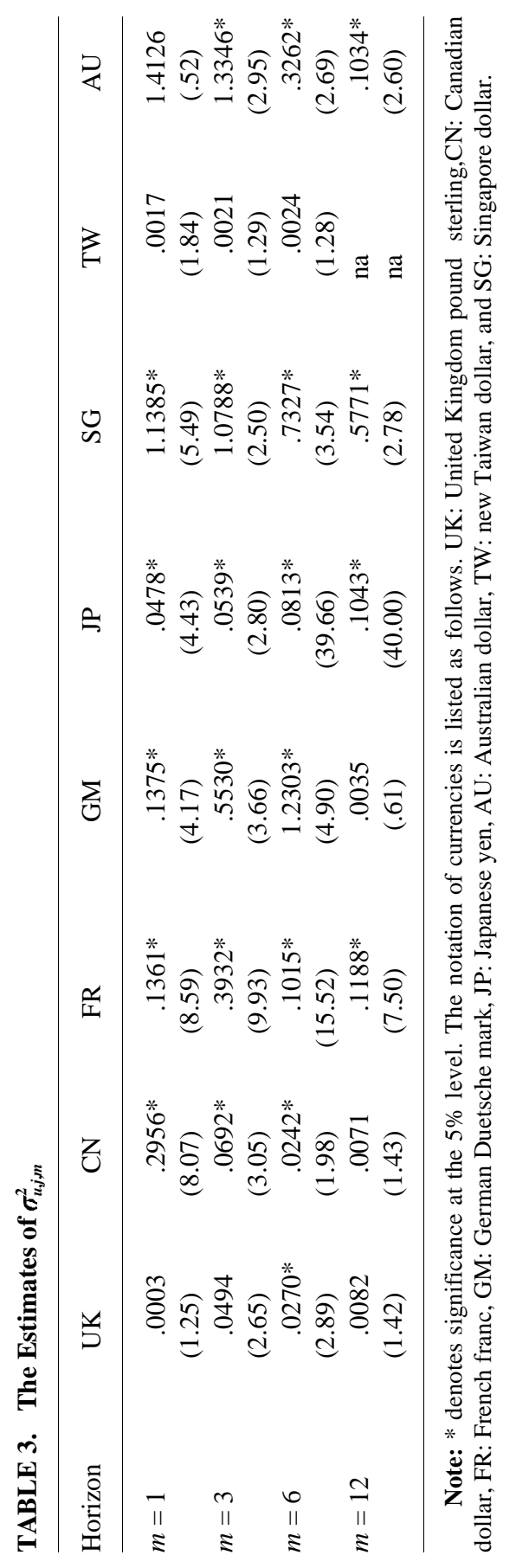


TABLE 4. Assessment of Forecasting Ability

\begin{tabular}{|c|c|c|c|c|c|c|c|}
\hline \multirow{2}{*}{\multicolumn{2}{|c|}{ Country Horizon }} & \multicolumn{2}{|c|}{ Equation 1} & \multicolumn{2}{|c|}{ Equation 6} & \multicolumn{2}{|c|}{$\%$ change of } \\
\hline & & Maple & $U^{*}$ & Maple & $U^{*}$ & Maple & $U^{*}$ \\
\hline \multirow[t]{4}{*}{ UK } & $m=1$ & 5.1961 & .0287 & .3535 & .0020 & -93.20 & -92.92 \\
\hline & $m=3$ & 9.9002 & .0515 & .8465 & .0049 & -91.45 & -90.54 \\
\hline & $m=6$ & 14.4335 & .0723 & 1.4611 & .0085 & -89.88 & -88.21 \\
\hline & $m=12$ & 20.1497 & .0977 & 2.2032 & .0132 & -89.07 & -86.50 \\
\hline \multirow[t]{4}{*}{$\mathrm{CN}$} & $m=1$ & 24.5539 & .0235 & 3.2373 & .0190 & -86.82 & -19.12 \\
\hline & $m=3$ & 31.6376 & .0438 & 3.2578 & .0187 & -89.7 & -57.26 \\
\hline & $m=6$ & 46.0219 & .0656 & 3.1994 & .0183 & -93.05 & -72.12 \\
\hline & $m=12$ & 49.0535 & .0978 & 3.2714 & .0187 & -93.33 & -80.90 \\
\hline \multirow[t]{4}{*}{ FR } & $m=1$ & 1.9964 & .0219 & .8676 & .0060 & -56.54 & -72.69 \\
\hline & $m=3$ & 2.8090 & .0251 & .9091 & .0061 & -67.64 & -75.75 \\
\hline & $m=6$ & 3.5354 & .0284 & .9650 & .0063 & -72.71 & -77.77 \\
\hline & $m=12$ & 3.9978 & .0308 & 1.0575 & .0068 & -73.55 & -77.73 \\
\hline \multirow[t]{4}{*}{ GM } & $m=1$ & 5.1374 & .0287 & 2.9062 & .0196 & -43.43 & -31.82 \\
\hline & $m=3$ & 8.4582 & .0470 & 7.5241 & .0699 & -11.04 & 48.79 \\
\hline & $m=6$ & 11.8446 & .0652 & 6.1856 & .0449 & -47.78 & -31.12 \\
\hline & $m=12$ & 16.3892 & .0903 & 10.3819 & .0759 & -36.65 & -15.94 \\
\hline \multirow[t]{4}{*}{ JP } & $m=1$ & .6285 & .0047 & .1893 & .0014 & -69.89 & -69.48 \\
\hline & $m=3$ & 1.1466 & .0078 & .2226 & .0016 & -80.59 & -78.82 \\
\hline & $m=6$ & 1.6577 & .0107 & .3499 & .0027 & -78.89 & -74.98 \\
\hline & $m=12$ & 2.4311 & .0151 & .3897 & .0025 & -83.97 & -83.13 \\
\hline \multirow[t]{4}{*}{ SG } & $m=1$ & 4.0533 & .0310 & 3.2760 & .0530 & -19.18 & 70.99 \\
\hline & $m=3$ & 5.9782 & .0389 & 3.3337 & .0539 & -44.23 & 38.42 \\
\hline & $m=6$ & 7.3483 & .0463 & 3.1546 & .0416 & -57.07 & -10.18 \\
\hline & $m=12$ & 10.5377 & .0614 & 3.0343 & .0290 & -71.21 & -52.75 \\
\hline \multirow[t]{3}{*}{ TW } & $m=1$ & 1.0158 & .0073 & .2388 & .0018 & -76.49 & -75.59 \\
\hline & $m=3$ & 1.1412 & .0080 & .2506 & .0018 & -78.04 & -77.40 \\
\hline & $m=6$ & 1.3143 & .0091 & .2628 & .0019 & -80 & -79.68 \\
\hline \multirow[t]{4}{*}{$\mathrm{AU}$} & $m=1$ & 7.8047 & .0455 & .0169 & .0001 & -99.78 & -99.77 \\
\hline & $m=3$ & 13.2208 & .0780 & .0436 & .0003 & -99.67 & -99.66 \\
\hline & $m=6$ & 16.8691 & .0976 & .0711 & .0004 & -99.58 & -99.54 \\
\hline & $m=12$ & 22.4226 & .1258 & .1034 & .0007 & -99.54 & -99.47 \\
\hline
\end{tabular}

Note: MAPE denotes the mean absolute percentage error and $U^{*}$ represents Theil $U^{*}$. UK: United Kingdom pound sterling, CN: Canadian dollar, FR: French franc, GM: German Duetsche mark, JP: Japanese yen, AU: Australian dollar, TW: new Taiwan dollar, and SG: Singapore dollar. 


\section{Concluding Remarks}

To comprehensively and thoroughly investigate the dynamic and stochastic behavior of currency betas based on the unbiasedness hypothesis (UH) under the logarithmic change specification, a number of novel statistical and econometric techniques were applied to cope with the problems of unit-roots, normality, autocorrelation, heteroscedasticity, and estimation inherent in the monthly data used to test the UH when forward contracts are involved.

The logarithmic change specification was further transformed into a variable mean response (VMR) random coefficients model incorporating the trend and four macroeconomic variables from different sectors of an economy. The four macroeconomic variables selected are UF (the unexpected shock of foreign exchange rates) and UR (the unexpected shock of interest rates) from the financial sector; RCS (the country stock return index) from the real sector; and TRIM (the ratio of total foreign reserves to imports) from the external sector. Eight countries (currencies) were considered in the empirical investigation. The eight countries were classified into two groups: the developed countries consisting of the United Kingdom, Canada, France, Germany, and Japan; and the developing (emerging) economies composed of Singapore, Taiwan, and Australia. Different tales from developed and emerging economies were discovered.

The findings are summarized as follows. First, currency betas are both dynamic and stochastic, rather than fixed, and are sensitive to special events. Second, the trend and macroeconomic variables contribute and lead to the fluctuating properties of currency betas. Third, the magnitude of the impacts of the macroeconomic variables vary from currency to currency: UF is found to be the most important contributor that causes currency betas to fluctuate over time, followed by TRIM for the group of developed countries, but by RCS which appears to have more impacts on the currency betas of the emerging economies than those of the developed countries; however, the directions of their influences are ambiguous. Fourth, explicit considerations of the changing behavior of currency betas substantially improve the accuracy of forecasting future spot rates. Fifth, the thesis that the forward rate is an unbiased predictor of the future spot rate is rejected by the data from the developed countries and the emerging economies as well. 
The empirical findings have at least four important implications. The forefront implication is that the time-varying and random patterns through time of currency betas invalidate the UH, i.e., cause the UH to be rejected. Then, the second implication follows. It implies that it is important to understand the structure of the UH. In its standard form, the UH is formed by three components, namely, the expected future spot rate, the currency beta, and the forward rate. The empirical evidence strongly suggests the foremost importance of the currency beta, although the question as to which component is the most important one is an empirical issue. The third implication relates to government and economic policies. In view of the fact that the interaction of macroeconomic variables causes currency betas to be dynamic and stochastic, the prudence of public and economic policies, especially, the foreign exchange policy, is crucial to stabilize the currency beta from time to time. The fourth implication points to the importance of understanding the dynamic and stochastic properties of the currency beta to the increase of the power of spot-rate forecasting.

In summary, we have provided more explicit information concerning the nature of the dynamic and stochastic currency beta, the specification of the heteroscedastic error, and the joint impacts of trend and macroeconomic factors upon the currency beta. The VMR randomly time-varying coefficients approach, equipped with several methods of analysis, permits a successful attempt to simultaneously test the important issues that concern the stochastic and dynamic behavior of currency betas, namely, nonstationarity, shifts in the mean and variance of the currency beta, and stochastics, the validity of the unbiasedness hypothesis, and the accuracy of forecasting future spot exchange rates. The empirical results have shown the fluctuating patterns of currency betas through time, and have important bearings on the validity of the unbiasedness hypothesis, public exchange rate policies, and the forecasts of future spot rates. Our analysis here explicitly distinguishes the stochastic and dynamic behavior of the currency betas of the developed countries from that of he emerging economies.

\section{References}

Baillie, R. T., and Bollerslev, T. 1989. Common stochastic trends in a system of exchange rates. Journal of Finance 44: 167-181. 
Bansal, R., and Dahlquist, M. 2000. The forward premium puzzle: Different tales from developed and emerging economies. Journal of International Economics 51: 115-144.

Barnhart, S. W., and Szakmary, A. C. 1991. Testing the unbiased forward rate hypothesis: Evidence on unit roots, co-integration, and stochastic coefficients. Journal of Financial and Quantitative Analysis 26: 245-267.

Barnhart, S. W.; McNown, R.; and Wallace, M. S. 1999. Non-informative tests of the unbiased forward exchange rate. Journal of Financial and Quantitative Analysis 34: 265-291.

Belsley, D. A., and Kuh, E. 1973. Time-varying parameter structures: An overview. Annals of Economic and Social Measurement 2: 375-378.

Bhawnani, V., and Kadiyla, K. R. 1997. Forecasting foreign exchange rates in developing countries. Applied Economics 29: 51-62.

Blanchard, O. J. 1981. Output, the stock market and interest rates. American Economic Review 71: 132-142.

Boothe, P., and Longworth, C. 1986. Foreign exchange market efficiency tests: Implications of recent empirical findings. Journal of International Money and Finance 5: 135-152.

Burstein, G. 1999. Macro-Trading and Investment Strategies. New York, NY: John Wiley \& Sons.

Chiang, T. C. 1988. The forward rate as a predictor of the future spot rate: A stochastic coefficient approach. Journal of Money, Credit, and Banking 20: 212-232.

Choi, J. J.; Hiraki, T.; and Takezawa, N. 1998. Is foreign exchange risk priced in the Japanese stock market? Journal of Financial and Quantitative Analysis 33: 361-232.

Cornell, B. 1977. Spot rates, forward rates, and exchange market efficiency. Journal of Financial Economics 5: 55-65.

Chu, M. L., and Tsaur, T. W. 1987. Outputs, stock markets, and the dynamic adjustment of foreign exchange rates. Academia Economic Papers 15: 45-59.

Dickey, D. A., and Fuller, W. A. 1979. Distribution of the estimators for autoregressive time series with a unit root. Journal of the American Statistical Association 74: 427-431.

Dickey, D. A., and Fuller, W. A. 1981. Likelihood ratio statistics for autoregressive time series with a unit root. Econometrica 49: 1057-1072.

Dickey, D. A., and Pantula, S. G. 1987. Determining the order of differencing in autogressive process. Journal of Business \& Economic Statistics 5: 455461.

Domowitz, I., and Hakkio, C. S. 1985. Conditional variance and the risk premium in the foreign exchange market. Journal of International Economics 19: 4766.

Fama, E. F. 1984. Forward and spot exchange rates. Journal of Monetary Economics 14: 319-338. 
Fisher, B. S., and Tanner, C. 1978. The formulation of price expectations: An empirical test of theoretical models. American Journal of Agricultural Economics 60: 245-248.

Ghysels, E. 1998. On stable factor structures in the pricing of risk: Do timevarying beta help or hurt? Journal of Finance 53: 549-573.

Gregory, A. W., and McCurdy, T. H. 1984. Testing the unbiasedness hypothesis in the forward foreign exchange market: A specification analysis. Journal of International Money and Finance 3: 357-368.

Hansen, L. P., and Hodrick, R. J. 1980. Forward exchange rates as optimal predictors of future spot rates: An econometric analysis. Journal of Political Economy 88: 829-853.

Henze, N., and Zirkler, B. 1990. A class of invariant consistent tests for multivariate normality. Communications in Statistical Theory and Methods 19: 3596-3617.

Hildreth, C., and Houck, J.P. 1968. Some estimators for a linear model with random coefficients. Journal of American Statistical Association 63: 584595.

Levich, R. M. 1979. On the efficiency of markets for foreign exchange. Chapter 7. In R. Dornbusch and J. A. Frenkel (eds.). International Economic Policy: Theory and Evidence. Baltimore, MD: Johns Hopkins University Press: 246266.

Lin, W.T. 1986. Analysis of lumber and pulpwood production in a partial adjustment model with dynamic and variable speeds of adjustment. Journal of Business \& Economic Statistics 4: 305-316.

Lin, W. T. 1988. The dynamic behavior of production in the extractive industry. Resources and Energy 10: 225-246.

Lin, W. T.; Chen, Y. H.; and Boot, J. C. G. 1992. The dynamic and stochastic instability of betas: Implications for forecasting stock returns. Journal of Forecasting 11: 517-541.

Lin, W. T., and Chen, Y. H. 1998. Forecasting foreign exchange rates with an intrinsically non-linear dynamic speed of adjustment model. Applied Economics 30: 295-312.

Lin, W. T. 1999. Dynamic and stochastic instability and the unbiased forward rate hypothesis: a variable mean response approach. Multinational Finance Journal 3: 173-221.

Lin, H. J., and Lin, W. T. 2000. A dynamic and stochastic beta and its implications in global capital markets. International Finance 3: 123-160.

Lo, A. W., and MacKinlay, A. C. 1999. Long-term memory in stock market prices. Chapter 6. In A Non-Random Walk Down Wall Street. Princeton, NJ: Princeton University Press.

Mardia, K. 1980. Measures of multivariate skewness and kurtosis with applications. Biometrika 67: 519-529.

Newey, W. K., and West, K. D. 1987. A simple, positive semi-definite, 
heteroskedasticity and autocorrelation consistent covariance matrix. Econometrica 55: 703-708.

Perron, P. 1988. Trends and random walks in macroeconomic time series, further evidence from a new approach. Journal of Economic Dynamics \& Control 12: 297-332.

Phillips, P. C. B., and Perron, P. 1988. Testing for a unit root in time series regression. Biometrika 75: 335-346.

Rosenberg, B. 1973. A survey of stochastic parameter regression. Annals of Economic and Social Measurement 2: 381-397.

Siegel, J. J. 1972. Risk, interest rates, and forward exchange. Quarterly Journal of Economics 86: 303-309.

Shapiro, S., and Wilk, M. 1965. An analysis of variance test for normality. Biometrika 52: 591-611.

Singh, B.; Nagar, A. L.; Choudhry, N. K.; and Raj, B. 1976. On the estimation of structural change, a generalization of the random coefficients regression model. International Economic Review 17: 340-61.

Taylor, M. 1995. The economics of exchange rates. Journal of Economic Literature 33: 13-47.

Theil, H. 1971. Principles of Econometrics. New York, NY: John Wiley \& Sons.

White, H. 1980. A heteroscedasticity-constant covariance matrix estimator, and a direct test for heteroscedasticity. Econometrica 48: 817-38.

Zarnowitz, V. 1985. Rational expectation and macroeconomic forecasts. Journal of Business and Economic Statistics 3: 293-311. 